\title{
Advanced glycation end products cause epithelial- myofibroblast transdifferentiation via the receptor for advanced glycation end products (RAGE)
}

\author{
Matthew D. Oldfield, ${ }^{1}$ Leon A. Bach, ${ }^{1}$ Josephine M. Forbes, ${ }^{1}$ David Nikolic-Paterson, ${ }^{2}$ \\ Anne McRobert, ${ }^{1}$ Vicki Thallas, ${ }^{1}$ Robert C. Atkins, ${ }^{2}$ Tanya Osicka, ${ }^{3}$ George Jerums, ${ }^{3}$ \\ and Mark E. Cooper ${ }^{1}$
}

\begin{abstract}
${ }^{1}$ Department of Medicine, University of Melbourne, Austin and Repatriation Medical Centre, Heidelberg, Australia ${ }^{2}$ Department of Nephrology, Monash Medical Centre, Clayton, Victoria, Australia

${ }^{3}$ Department of Endocrinology, University of Melbourne, Austin and Repatriation Medical Centre, Heidelberg, Australia

Address correspondence to: Mark E. Cooper, Department of Medicine, Austin and Repatriation Medical Centre, Austin Hospital, Studley Road, Heidelberg, Victoria 3084, Australia.

Phone: 61-3-9496-5387; Fax: 61-3-9457-5485; E-mail: cooper@austin.unimelb.edu.au.
\end{abstract}

Received for publication December 6, 2000, and accepted in revised form October 1, 2001.

\begin{abstract}
Tubulointerstitial disease, a prominent phenomenon in diabetic nephropathy, correlates with decline in renal function. The underlying pathogenic link between chronic hyperglycemia and the development of tubulointerstitial injury has not been fully elucidated, but myofibroblast formation represents a key step in the development of tubulointerstitial fibrosis. RAGE, the receptor for advanced glycation end products (AGEs), induces the expression of TGF- $\beta$ and other cytokines that are proposed to mediate the transdifferentiation of epithelial cells to form myofibroblasts. Here we report specific binding of ${ }^{125}$ I-AGE-BSA to cell membranes prepared from a rat proximal tubule cell line and show that the binding site was RAGE. AGE exposure induced dose-dependent epithelial-myofibroblast transdifferentiation determined by morphological changes, de novo alpha smooth-muscle actin expression, and loss of epithelial E-cadherin staining. These effects could be blocked with neutralizing Ab's to RAGE or to TGF- $\beta$. Transdifferentiation was also apparent in the proximal tubules of diabetic rats and in a renal biopsy from a patient with type 1 diabetes. The AGE cross-link breaker, phenyl-4,5-dimethylthiazolium bromide (ALT 711) reduced transdifferentiation in diabetic rats in association with reduced tubular AGE and TGF- $\beta$ expression. This study provides a novel mechanism to explain the development of tubulointerstitial disease in diabetic nephropathy and provides a new treatment target.
\end{abstract}

J. Clin. Invest. 108:1853-1863 (2001). DOI:10.1172/JCI200111951.

\section{Introduction}

Nonenzymatic glycation is a ubiquitous reaction between reducing sugars and polypeptides that ultimately generates irreversibly advanced glycated end products (AGEs). Advanced glycation occurs during normal aging but to a greater degree in diabetes (1), where there is now increasing evidence of a causal role for AGEs in the development of diabetic complications, including nephropathy $(2,3)$. AGEs exert effects both directly through the formation of protein cross-links that alter the structure and function of ECM and by interacting with specific cell surface receptors. The best characterized of the AGE receptors has been called the receptor for advanced glycation end products (RAGE) (4), although other AGE-binding sites have also been reported (5-7). Interactions between AGEs and their binding proteins lead to the activation of a range of secondary messenger systems and increases the production of cytokines, including TGF- $\beta$, PDGF, and IL-1 (8-10). Recently, compounds that can cleave established AGE cross-links (11), such as ALT 711, a stable 4,5-dimethylthiazolium derivative of the prototype compound $\mathrm{N}$-phenyl-thia- zolium bromide, have been investigated. In vivo efficacy has been demonstrated in animal models, showing that these compounds can result in reduced AGE accumulation (12) and can reverse age- and diabetes-dependent increases in arterial stiffness $(13,14)$.

There are positive correlations between the degree of interstitial fibrosis and the decline of renal function (15, 16). The myofibroblast, a cell with biochemical and structural features of both the smooth muscle cell and the fibroblast, is a major contributor to ECM accumulation in fibrotic disease (17), and myofibroblast numbers correlate with renal function in diabetic nephropathy (18). The origin of these cells is not fully elucidated; however, transdifferentiation of proximal tubular cells into myofibroblasts is now suggested as a mechanism of myofibroblast formation (19). Recent data have shown that proximal tubular cells undergo transdifferentiation in the presence of the cytokine TGF- $\beta$ (20). Although it has been shown that tubulointerstitial injury is a prominent feature of diabetic nephropathy, the possibility that there is proximal tubular transdifferentiation in diabetes has not been examined. The aim of the present study was 
to address whether AGEs could cause proximal tubular cell transdifferentiation and, furthermore, to explore the role of TGF- $\beta$ in this process.

\section{Methods}

Cell culture. The well-characterized normal rat kidney epithelial cell line (NRK-52E) was obtained from the American Tissue Culture Collection (Rockville, Maryland, USA). NRK-52E cells are believed to be of a proximal tubular origin on the basis of patterns of collagen secretion, C-type natriuretic peptide secretion, and the presence of EGF receptors (20). Cells were maintained in DMEM containing $4.5 \mathrm{~g} / 1$ glucose (Sigma Chemical Co., St. Louis, Missouri, USA) with $10 \%$ FCS at $37^{\circ} \mathrm{C}$ in a $5 \% \mathrm{CO}_{2}$ atmosphere and passaged twice a week.

In vitro preparation of ligands. AGE-BSA and AGE-RNase were prepared by incubating BSA $(10 \mathrm{mg} / \mathrm{ml})$ or RNase $(10 \mathrm{mg} / \mathrm{ml})$ at $37^{\circ} \mathrm{C}$ for 6 weeks with D-glucose $(90 \mathrm{~g} / \mathrm{l})$ (Sigma Chemical Co.) in a $0.4-\mathrm{M}$ phosphate buffer containing azide (21). Control preparations were treated identically except that glucose was omitted. Finally, preparations were extensively dialyzed against phosphate buffer to remove free glucose. The extent of advanced glycation was assessed by characteristic fluorescence (excitation 370, emission $440 \mathrm{~nm}$ ) (3). Advanced glycation was associated with an approximately tenfold increase in fluorescence compared with controls.

Carboxymethyl lysine-modified (CML-modified) BSA was prepared as described previously (22). Briefly, $50 \mathrm{mg} / \mathrm{ml}$ aliquots of BSA were incubated with increasing concentrations of glyoxylic acid $(5-90 \mathrm{mM})$ in the presence of approximately fivefold molar excess of sodium cyanoborohydride. Control proteins were prepared under the same conditions, except that glyoxylic acid was omitted. The extent of chemical modification of lysine residues was determined as described previously using 2,4,6-trinitrobenzenesulfonic acid (23). The extent of lysine modification was up to $34 \%$ for CMLBSA preparations and $77 \%$ for AGE-modified proteins.

Iodination of AGE-BSA. AGE-BSA was iodinated by incubating AGE-BSA with chloramine-T (24). Bound ${ }^{125}$ I was separated from free ${ }^{125}$ I using a Biogel (Bio-Rad Laboratories Inc., Hercules, California, USA) P6DG desalting gel. Specific activity of the tracer was $400 \mathrm{Ci} / \mathrm{mM}$.

Membrane preparation. Membranes were prepared based on the method of Skolnik (25). NRK-52E cells were grown to confluence in $150-\mathrm{cm}^{2}$ tissue-culture flasks. Cells were washed twice with PBS, then detached from plates using a HEPES $(100 \mathrm{mM})$ solution containing BSA $(0.1 \%)$ and Triton X-100 (0.1\%) with EDTA $(5 \mathrm{mM})$, leupeptin $(1 \mu \mathrm{M})$, and PMSF $(2 \mathrm{mM})$. Cells were centrifuged for 5 minutes at $2,000 \mathrm{~g}$ and resuspended in the above buffer before disruption by ultrasound. Cell debris was removed by further centrifugation $(10 \mathrm{~m}$ at $2,000 \mathrm{~g})$ and the supernatant ultracentrifuged at $100,000 \mathrm{~g}$ (Beckman Instruments, Oakleigh, Australia) for 1 hour at $4^{\circ} \mathrm{C}$. The supernatant was discarded, and the cell membranes in the precipitate were resolubilized in the above buffer. Protein concentrations were deter- mined by the method of Bradford (26). The membrane preparation was used in binding studies and for ligand and Western blot analysis.

Binding studies. Cell membrane extracts were incubated with ${ }^{125}$ I-AGE-BSA $(0.5 \mathrm{nM})$ and increasing concentrations of unlabeled AGE-BSA $(0.015-7.46 \mu \mathrm{mol})$ for 3 hours at $4^{\circ} \mathrm{C}$ in HEPES $(100 \mathrm{mM})$ binding buffer with BSA $(0.1 \%)$, Triton X-100 (0.1\%), leupeptin $(1 \mu \mathrm{M})$, and PMSF (2 mM). A Brandel cell filter (Biomedical Research and Development Laboratories, Gaithersburg, Maryland, USA) was used to separate bound and free radioligand. A Tris- $\mathrm{HCl}(10 \mathrm{mM})$ polyethylene glycol $(6.6 \%)$ buffer was used to wash components through the apparatus onto glass filter papers, which were counted in a $\gamma$-counter (Wallac, Turku, Finland) for 1 minute. Binding experiments were performed in duplicate in five separate experiments, and the specificity of binding was assessed in further experiments using unlabeled, unmodified BSA $(1 \mu \mathrm{mol})$ as the competitor. Binding data were analyzed using a specific binding program (LIGAND; ref. 27).

Ligand and Western blot analysis. Cell membrane extracts (20 $\mu \mathrm{g}$ of membrane protein per lane) were subjected to nonreducing SDS (12-15\%) PAGE and electroblotted onto nitrocellulose membranes (Hybond; Amersham Pharmacia Biotech, Castle Hill, Australia). For ligand blotting the membranes were blocked overnight at $4^{\circ} \mathrm{C}$ in a Tris (10 mM, pH 7.4), $\mathrm{NaCl}(150 \mathrm{mM})$, Tween (0.1\%) buffer containing BSA (2.5\%), before incubation with ${ }^{125} \mathrm{I}-\mathrm{AGE}-\mathrm{BSA}(110 \mathrm{ng} / \mathrm{ml})$ for 2 hours at room temperature. After washing with Tris ( $10 \mathrm{mM}, \mathrm{pH} 7.4), \mathrm{NaCl}(150$ $\mathrm{mM}$ ), and Tween (0.1\%), the membrane was exposed to Kodak Biomax MS film (Eastman Kodak Co., Rochester, New York, USA) for 1-4 hours. Receptor-ligand binding specificity was studied in competitive experiments where unlabeled AGE-BSA, AGE-RNase, BSA, and RNase (all $100 \mu \mathrm{g} / \mathrm{ml}$ ) were added as competing ligands.

In Western blotting experiments, the nitrocellulose membrane was incubated at room temperature for 1 hour with a polyclonal goat $\mathrm{Ab}$ against human RAGE 1:2,000 (gift of M. Neeper, Merck, West Point, Pennsylvania, USA) $(28,29)$. Membranes were washed before a 15-minute incubation with a biotinylated secondary $\mathrm{Ab}$ (DAKO Corp., Carpinteria, California, USA) and a streptavidin-horseradish peroxidase conjugate (Vector Laboratories, Burlingame, California, USA). Immunoreactivity was detected using an enhanced chemiluminescence kit (Amersham Pharmacia Biotech) and exposure to Kodak Biomax MR film. Recombinant RAGE (gift of K. Jansen, Merck, West Point, Pennsylvania, USA), 900 ng per lane, and bovine lung extract, $30 \mu \mathrm{g}$, were loaded onto gels as positive controls. Primary Ab's were omitted in experiments as negative controls and RAGE Ab specificity was confirmed by preincubation of the membrane with recombinant RAGE before the addition of RAGE Ab.

To further explore the lower-molecular-weight band seen on ligand blotting, Western blotting experiments were performed with a primary Ab to lysozyme, 1:1,000 


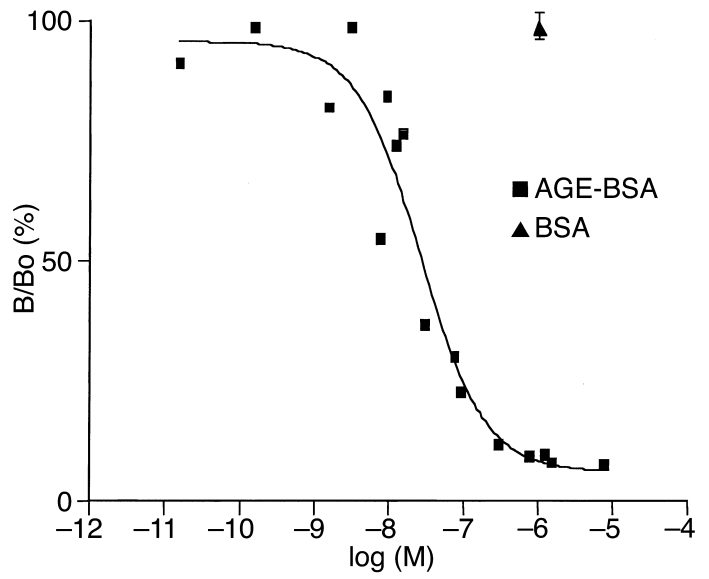

Figure 1

Binding of AGEs to NRK 52E cell membranes. Unlabeled AGE-BSA (filled squares) competed with ${ }^{125}$ I AGE-BSA for membrane binding; unglycated BSA (filled triangles) did not. Shown is one representative of five independent experiments. Maximal binding was defined as binding in the absence of competition and was $4.27 \pm 0.4 \%$ of applied radioactivity. Nonspecific binding was defined as binding in the presence of maximal competition (10-4 M AGE-BSA) and was $7.7 \pm 0.6 \%$ of maximal binding. $\mathrm{B} / \mathrm{Bo}(\%), \%$ specific binding.

(RB-372-A1; Lab Vision NeoMarkers, Fremont, California, USA). Lysozyme (10 $\mu \mathrm{g})$ was added to the gel as a positive control.

Transdifferentiation. The cells were grown to confluence on eight-well glass slides (Nalge Nunc International, Naperville, Illinois, USA). The media was changed to DMEM supplemented with $1 \%$ FCS. Cells were then cultured for 2, 4, and 6 days in the presence of AGE-modified BSA (AGE-BSA, 5-40 $\mu \mathrm{M}$ ), AGE-ribonuclease (AGERNase, $100 \mu \mathrm{M})$, or with the same nonglycated proteins as controls. In further experiments, cells were incubated for 6 days with variously CML-modified BSA $(200 \mu \mathrm{M})$ or control. In separate experiments, anti-human RAGE $\mathrm{Ab}(1: 200)$ (28), or neutralizing Ab to TGF- $\beta$ (MAB 240, $10-20 \mu \mathrm{g} \mathrm{ml}$; R\&D Systems Inc., Minneapolis, Minnesota, USA) were added to evaluate the role of RAGE and TGF- $\beta$ in transdifferentiation. Azide-free control mouse monoclonal or rabbit polyclonal Ab's (Santa Cruz Biotechnology Inc., Santa Cruz, California, USA) were added at identical $\mathrm{Ab}$ concentrations. Fresh media containing AGE-proteins and Ab's were replaced at 3 days. Light microscopy and immunocytochemistry. At the end of the incubations described above, cells were examined for changes in cell morphology by light microscopy $(\times 200-400)$ and antigen expression by immunohistochemistry. Cells were stained for the myofibroblast marker alpha-smooth muscle actin ( $\alpha$-SMA) $(30,31)$. As a further marker of transdifferentiation, cells were examined for the presence of the epithelial junctional protein E-cadherin in parallel experiments, as described previously (20).

Immunohistochemistry. Ab's used were to $\alpha$-SMA (1A4; DAKO Corp.), a well-characterized Ab recognizing AGE (28), and RAGE (gift of M. Neeper) $(28,29)$. Ab's to
TGF- $\beta$ (MAB 1835; R\&D Systems Inc.) and E-cadherin (C37020; Transduction Laboratories, San Diego, California, USA) were used at $5 \mu \mathrm{g} / \mathrm{ml}$.

Cells were fixed in $4 \%$ paraformaldehyde by the acidshift method (32). To aid E-cadherin antigen retrieval fixed cells were treated with 10 minutes of microwave oven heating in citrate buffer $(10 \mathrm{mM}, \mathrm{pH} 6.0)$ at 2,450 $\mathrm{MHz}$ and at $800 \mathrm{~W}$ of power.

Kidney tissues examined for $\alpha$-SMA, AGE, and RAGE were formalin fixed, and tissues used for TGF- $\beta$ staining were fixed in mercuric chloride.

In general, staining followed standard procedures using an avidin-biotin-based $\mathrm{Ab}$ system. Nonspecific binding was prevented by incubation with $10 \%$ normal goat serum, and cells and tissues were incubated sequentially with the primary $\mathrm{Ab}, 0.3 \%$ hydrogen peroxide in PBS, and a biotinylated secondary Ab (DAKO Corp.). Finally, streptavidin-conjugated horseradish peroxidase (Vector Laboratories Inc.) was added, followed by signal development using diaminobenzidine (DAB; DAKO Corp.) for AGE, RAGE, SMA, and TGF- $\beta$ or novo red (E-cadherin) as substrate.

In vivo transdifferentiation. Two normotensive rat models were studied, Wistar Kyoto (WKY) and Sprague Dawley (SD) rats, to allow comparison of transdifferentiation at various time points. Both strains were chosen because our group has previously characterized the evolution of diabetic nephropathy in detail in these animals $(33,34)$. At age 8 weeks, rats were randomized into two groups, control and diabetic. Diabetes was induced by intravenous injection of streptozotocin (STZ) $50 \mathrm{mg} / \mathrm{kg}$, after an overnight fast. Only rats with plasma glucose of more than $15 \mathrm{mmol} / \mathrm{l}$ were considered diabetic. All diabetic animals received $2 \mathrm{U}$ insulin/zinc suspension (Ultratard HM; Novo Nordisk, Bagsvaerd, Denmark) injected subcutaneously three times a week to maintain body weight and improve survival. The SD rats were further randomized to receive the cross-link breaker, ALT-711, at 10 $\mathrm{mg} / \mathrm{kg} /$ day or nothing by gavage (14). These thiazolium
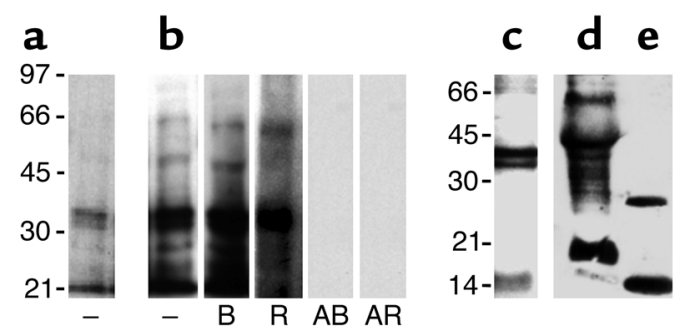

Figure 2

Ligand and Western blot analysis of NRK 52E membrane proteins. (a) Ligand blot analysis of membrane preparations, SDS-12\% PAGE, using ${ }^{125}$ I AGE-BSA revealed major binding sites sized $35 \mathrm{kDa}$ and 21 $\mathrm{kDa}$. (b) Competitive incubations of radioligand with AGE-proteins (AB, AGE-BSA; AR, AGE-RNase) and unglycated proteins (B, BSA; $\mathrm{R}, \mathrm{RNase}$ ), all $100 \mu \mathrm{g} / \mathrm{ml}$, demonstrating AGE binding specificity. Western blotting of cell membrane proteins using anti-human RAGE $\mathrm{Ab}(\mathbf{c})$, and anti-human lysozyme (d and $\mathbf{e})$. Lysozyme $(10 \mu \mathrm{g})$ was used as positive control (e). The migration of molecular-weight markers run simultaneously is indicated in kilodaltons. 


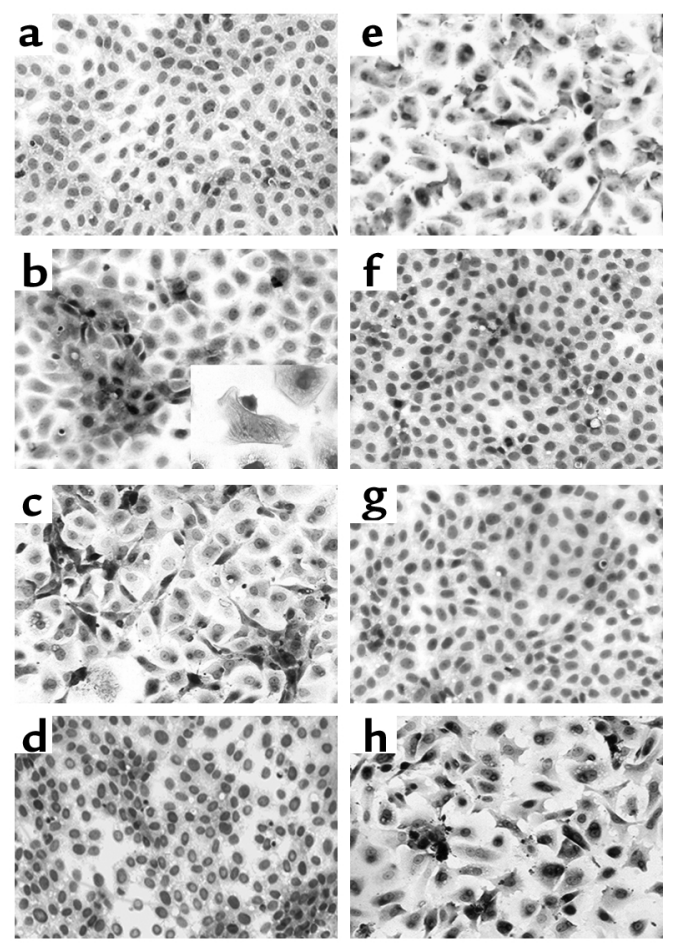

Figure 3

Exposure to AGEs causes a dose-dependent change in phenotype and antigen expression. After 6 days under experimental conditions, cultured cells were stained for $\alpha$-SMA. (a) NRK 52E cells in media alone. (b) AGE-BSA $(20 \mu \mathrm{M})$. Insert shows positive $\alpha$-SMA staining in longitudinal microfilaments. (c) AGE-BSA $(40 \mu \mathrm{m})$. (d) Unglycated BSA. (e) AGE-RNAse $(100 \mu \mathrm{M})$. (f) AGE-BSA $(40 \mu \mathrm{M})$ and Ab's to the RAGE receptor, (g) TGF- $\beta$, and (h) control Ab's. Original magnification, $\times 200$; except insert in $\mathbf{b}, \times 400$.

compounds have been shown previously to specifically cleave preformed AGEs (11) and are associated with reduced AGE accumulation (12).

WKY rats were sacrificed after 16 and 24 weeks and the SD rats at 32 weeks. Kidneys were formalin fixed and paraffin embedded. Sections from diabetic and control animals $(n \geq 5)$ at each time point were stained for $\alpha$-SMA as per cell culture experiments and counterstained with periodic acid-Schiff reagent (PAS) to aid the identification of basement membranes and brush borders.

One animal that failed to become diabetic after STZ administration was used as a control for nonspecific effects of STZ.

In addition, a number of human biopsy samples from type 1 diabetic subjects with nephropathy were stained and examined for tubular $\alpha$-SMA immunostaining. A number of postmortem samples from patients with diabetic nephropathy were also obtained and examined for the presence of AGE and RAGE.

Quantitation of immunocytochemical staining. Slides were blinded for identity and more than ten high-power fields ( $\times 400$, approximately 300 cells per field) were counted with the aid of a graticule to identify cells expressing $\alpha$-SMA or E-cadherin.
In animal experiments tubules containing $\alpha$-SMA positive (+ve) cells were counted with more than 40 high-power fields per section and expressed as a proportion of total tubule number. In the ALT 711 study the proportion of $\alpha$-SMA +ve cells in each affected tubule was also quantitated. The observer was blinded as to the status of each section. Results are shown as the percentage of $\alpha$-SMA +ve tubules of total tubules counted and percentage of $\alpha$-SMA +ve cells per affected tubule.

Tubular TGF- $\beta$ immunostaining performed in the SD rat group was quantitated using a computerized imaging system as described previously (35). Areas including tubules only were selected, and proportional immunostaining was assessed in more than 40 high-power fields, with observers masked as to slide identity. Results are expressed as the proportional stained area.

TGF- $\beta$ analysis. NRK 52E cells were passaged into sixwell plates and treated as above with AGEs or unmodified proteins in the presence or absence of Ab's. After 3 days, the media was removed and analyzed for TGF- $\beta$ using a sandwich ELISA kit (Promega Corp., Annandale, Australia) per the manufacturer's instructions. Total TGF- $\beta$ was measured in duplicate samples from three separate experiments and final TGF- $\beta$ concentrations adjusted for cell number.

Statistical analysis. Values are means plus or minus SEM. Data were analyzed by ANOVA and compared using Tukey post hoc test. A two-tailed unpaired $t$ test was used to compare control and diabetic animals for $\alpha$-SMA staining. $P$ values less than 0.05 were considered significant.

\section{Results}

AGE-binding site. Competitive binding studies showed that ${ }^{125}$ I-AGE-BSA bound specifically to NRK 52E cell membranes (Figure 1). AGE-BSA, but not nonglycated BSA effectively competed with radioligand for binding. Analysis of binding data using LIGAND showed single-site binding with an association constant of $2.7 \pm 0.5 \times 10^{7} \mathrm{M}^{-1}$ and half-maximal binding of $36 \mathrm{nM}$.

\section{Table 1}

Clinical characteristics

\begin{tabular}{|c|c|c|c|}
\hline Group & $n$ & $\begin{array}{l}\text { Weight } \\
\text { (g) }\end{array}$ & $\begin{array}{l}\text { Glucose } \\
(\mathrm{mmol} / \mathrm{l})\end{array}$ \\
\hline
\end{tabular}

WKY

$\begin{array}{lllrc}\text { Control 16 week } & 6 & 427 \pm 7 & 6.0 \pm 0.2 & 3.1 \pm 0.8 \\ \text { Control 24 week } & 6 & 431 \pm 8 & 5.9 \pm 0.2 & 4.4 \pm 0.2^{\mathrm{A}} \\ \text { Diabetic 16 week } & 6 & 331 \pm 12^{\mathrm{A}} & 23.8 \pm 1.8^{\mathrm{A}} & 11.8 \pm 0.5^{\mathrm{A}} \\ \text { Diabetic 24 week } & 6 & 316 \pm 15^{\mathrm{A}} & 27.7 \pm 0.7^{\mathrm{A}} & 12.6 \pm 0.5^{\mathrm{A}} \\ \text { SD } & & & & \\ \text { Control 32 week } & 5 & 694 \pm 20 & 6.3 \pm 0.5 & 4.5 \pm 0.5^{\mathrm{A}} \\ \text { Diabetic 32 week } & 5 & 516 \pm 40^{\mathrm{A}} & 26.4 \pm 0.4^{\mathrm{A}} & 15.7 \pm 1.6^{\mathrm{A}} \\ \text { Diabetic 32 week } & 5 & 529 \pm 50^{\mathrm{A}} & 26.0 \pm 0.4^{\mathrm{A}} & 16.6 \pm 2.4^{\mathrm{A}}\end{array}$
+ ALT-711

Data are mean \pm SEM. ${ }^{A} P<0.01$ vs. control. 
To further characterize this binding site, ligand blot analysis of the membrane preparations was performed. Major ${ }^{125}$ I-AGE-BSA binding sites sized 30-35 kDa and $21 \mathrm{kDa}$ were revealed (Figure $2 \mathrm{a}$ ). To assess the specificity of ${ }^{125}$ I-AGE-BSA binding at these sites the experiment was repeated in the presence of unlabeled AGEs and unlabeled, non-AGE-modified proteins in excess (Figure 2b). AGE-BSA and AGE-RNase completely inhibited radioligand binding, whereas unmodified BSA and RNase did not, suggesting that observed binding was specific for the AGE epitope.

The binding characteristics and the observed molecular weight of the $35-\mathrm{kDa}$ site was similar to that published previously for the RAGE receptor (4). This led us to further explore the identity of this binding protein by immunoblotting with the RAGE Ab (Figure 2c). This confirmed that the $30-35 \mathrm{kDa}$ doublet seen on the ligand blot represented RAGE.

The lower-molecular-weight band seen on the ligand blot was considered to possibly represent the presence of lysozyme in our preparation, because lysozyme has been shown previously to bind to AGEs (36). Immunoblotting using an $\mathrm{Ab}$ to lysozyme failed to bind to the 14 - to $21-\mathrm{kDa}$ band seen in our RAGE immunoblot (Figure 2, $d$ and e), suggesting that this band was not lysozyme. The identification of RAGE in this cell line and its relevance to our in vitro system was further explored by repeating transdifferentiation studies in the presence of Ab to RAGE (see below).

Morphological and immunohistological demonstration of AGE-mediated transdifferentiation of NRK $52 \mathrm{E}$ cells. The effects of AGE exposure on NRK 52E cells were examined through changes in light-microscopic appearance and alterations in antigen expression. NRK 52E cells cultured in media alone grow as a confluent monolayer with a typical "cobblestone" appearance (Figure 3a). Incubation with AGE-BSA caused progressive morphological changes, including initial cellular hypertrophy and dissociation of neighboring cells, indicative of a more invasive phenotype. Ultimately, a "fibroblastlike" appearance was attained (Figure 3, b-c). There was no effect on morphology when cells were incubated with the nonglycated control protein (Figure $3 \mathrm{~d}$ ).

$\alpha$-SMA expression is considered to be a characteristic immunological marker for the myofibroblast $(30,31)$. Untreated NRK cells rarely expressed $\alpha$-SMA (Figure $3 a$ and Figure 4). However, exposure of cells to AGEs caused a dose- and time-dependent increase in $\alpha$-SMA expression (Figure 3, b-c; Figure 4, a and b). Approximately $75 \%$ of cells expressed $\alpha$-SMA after 6 days when incubated with AGE-BSA $(40 \mu \mathrm{M})(P<0.001$; ANOVA). Cells incubated in the presence of unglycated BSA had a similar level of $\alpha$-SMA expression as untreated cells (Figure 3d). To confirm that advanced glycation was responsible for transdifferentiation, a further experiment using AGE-RNase and unglycated RNase was performed (Figure 3e; AGE-RNase only shown). Typical morphological changes and the development of $\alpha$-SMA staining occurred in the presence of AGE-modified RNase, but not with the unglycated protein.

To further explore the role of RAGE and the cytokine TGF- $\beta$, neutralizing Ab's to either RAGE, TGF- $\beta$, or control Ab's were added to the system in separate experiments (Figure 3, f-h, and Figure 4a). AGEdependent changes in phenotype and $\alpha$-SMA staining were completely abrogated by the addition of an $\mathrm{Ab}$ to a

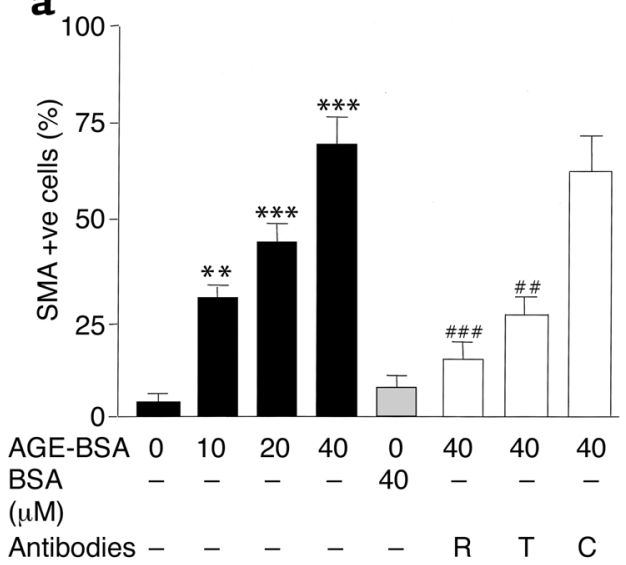

b

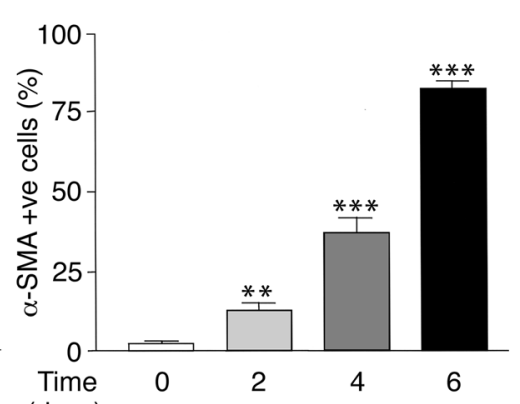

(days) c

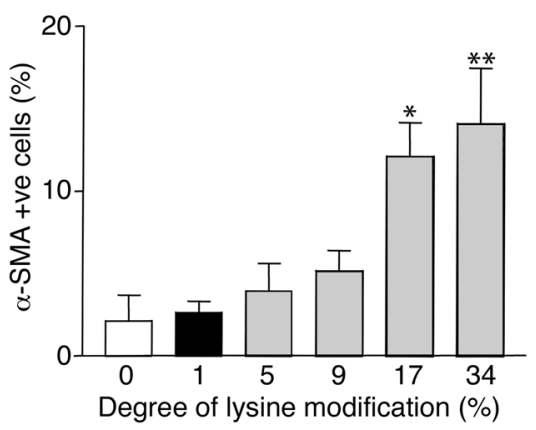

Figure 4

Time- and dose-dependent $\alpha$-SMA expression by NRK 52E cells. (a) Cells cultured in the presence of increasing concentrations of AGE-BSA or unglycated BSA, in the presence or absence of Ab's to RAGE, TGF- $\beta$, or control Ab's, were counted in three or more separate experiments. Represented are $\alpha-S M A+v e$ cells counted in ten or more high-power fields $(\times 200)$ expressed as a percentage of total cell number (mean \pm SEM). ${ }^{*} P<0.01,{ }^{* *} P<0.001$ compared with untreated cells. The observed increase in $\alpha$-SMA staining with AGE-BSA ( $\left.40 \mu \mathrm{M}\right)$ was prevented by $A b$ 's to either RAGE (R) or to TGF- $\beta$ (T), but not by control Ab's $(C)$. ${ }^{\#} P<0.01$, \#\#\# $P<0.001$ compared with AGE-BSA (40 $\mu M$ ). (b) Effects of exposure of NRK cells to AGE-BSA $(40 \mu \mathrm{M})$ over time. Cells were examined at 2, 4, and 6 days in three or more separate experiments; ${ }^{*} P<0.01$, ${ }^{*}{ }^{*} P<0.001$ compared with 0 days. (c) Effects of exposure of NRK cells to CML-modified BSA. Variously, CML-modified BSA was prepared by incubating BSA with sodium cyanoborohydride, in the presence or absence of glyoxylic acid. Incubation of NRK cells in the presence of CML-BSA $(200 \mu \mathrm{M})$ caused a modification-dependent increase in $\alpha$-SMA staining. Shown are results of three or more independent experiments; degree of lysine modification versus SMA positive cells as percentage of total cell number (mean \pm SEM). ${ }^{*} P<0.05,{ }^{*} P<0.01$. 


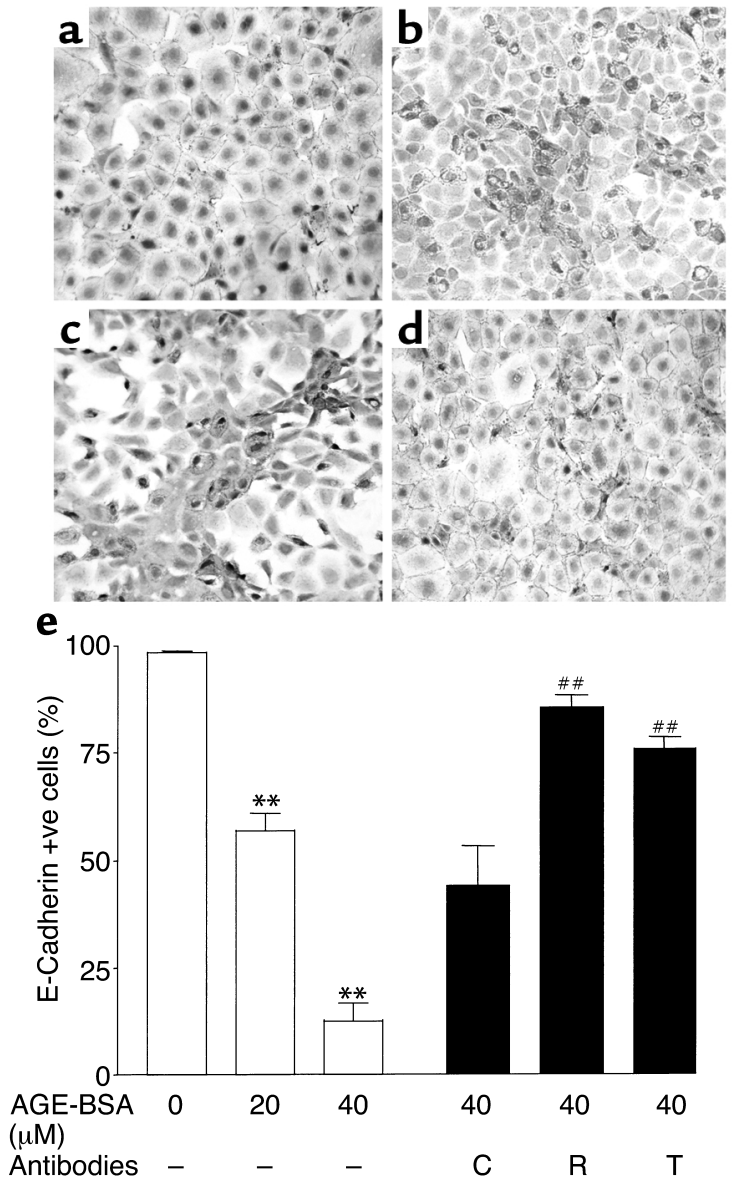

Figure 5

E-cadherin expression is lost in cells cultured with AGE-BSA. After 6 days under experimental conditions, cells were stained for E-cadherin. (a) NRK 52E cells grown in media alone. (b) Culture with AGE-BSA $(20 \mu \mathrm{M}),(\mathbf{c})$ AGE-BSA $(40 \mu \mathrm{M})$. (d) Cells cultured with AGE-BSA (40 $\mu \mathrm{M})$ and neutralizing $A b$ to RAGE. Original magnification, $\times 200$. (e) $\mathrm{E}$-cadherin quantitation. Cells expressing E-cadherin were counted in six or more high-power fields $(\times 400)$ and expressed as a percentage of total cell number (mean $\pm S E M$ ). Coincubation in the presence of Ab's to RAGE (R) or TGF- $\beta$ (T) abrogated the expected E-cadherin loss, whereas control $A b$ 's $(C)$ did not. ${ }^{*} P<0.01$ compared with untreated cells; ${ }^{\# \#} P<0.01$ compared with AGE-BSA $(40 \mu \mathrm{M})$ by ANOVA.

RAGE (Figure 3f; $P<0.001$, ANOVA). The addition of a TGF- $\beta$-neutralizing $\mathrm{Ab}(20 \mu \mathrm{g} / \mathrm{ml})$ also largely prevented AGE-dependent increases in $\alpha$-SMA expression (Figure 3g; $P<0.01$, ANOVA). AGE-mediated changes in cell morphology and $\alpha$-SMA staining were not prevented by the presence of control Ab's (Figure 3h), indicating specific actions of Ab's to RAGE and TGF- $\beta$.

Manufacture of AGEs in the laboratory creates highly modified molecules that may have limited in vivo relevance. CML is a known in vivo modification that has been shown previously to bind to RAGE (22) and was assessed in this system. Exposure of cells to CML-BSA ( $200 \mu \mathrm{M}$ BSA equivalent, $34 \%$ lysine modification) was associated with an increase in $\alpha$-SMA staining in $14.1 \pm 3.3 \%$ of cells (Figure $4 \mathrm{c} ; n=4, P<0.01$, ANOVA), with only an occasional cell changing to a fibroblast phenotype. Lesser CML modifications of free lysine on the BSA molecule induced lesser increases in $\alpha$-SMA expression (5\% lysine modification, $4.0 \pm 1.6 \%$; $9 \%$ modification, $5.2 \pm 1.2 \%$; $17 \%$ modification, $12.1 \pm 2.1 \%$; mean \pm SEM shown, $n=4$ per group, $P<0.05$, ANOVA) with no evidence of phenotypic changes in the cells.

Loss of the epithelial cell antigen E-cadherin was also examined as a further phenotypic marker of transdifferentiation (Figure 5). Confluent cultures of NRK 52E cells nearly all expressed immunostainable E-cadherin (Figure 5a). Exposure to AGE-BSA caused a dosedependent loss of E-cadherin expression in a largely reciprocal pattern to increasing $\alpha$-SMA staining (Figure 5, b, c, and e). After 6 days of exposure to AGE-BSA $(40 \mu \mathrm{M})$, E-cadherin expression was lost in approximately $85 \%$ of cells (Figure 5 c; $P<0.01$, ANOVA). Cultured cells exposed to unglycated BSA maintained similar E-cadherin expression to untreated cells. The addition of Ab's to RAGE or TGF- $\beta$, but not control Ab's, prevented AGE-mediated loss of E-cadherin $(P<0.01$, ANOVA; Figure $5, \mathrm{~d}$ and e; cells cultured with AGE, $40 \mu \mathrm{M}$, and RAGE only shown).

TGF- $\beta$ expression. TGF- $\beta$ has been shown previously to mediate transdifferentiation and was considered to be a likely candidate cytokine within our system. The exposure of NRK 52E cells to AGEs caused a significant dose-dependent increase in total TGF- $\beta$ protein production at 3 days from approximately $5 \mathrm{ng} / \mathrm{ml}$ untreated to nearly $12 \mathrm{ng} / \mathrm{ml}$ after exposure to the higher AGE concentration (Figure 6; $P<0.05$ ). This effect was blocked by the presence of RAGE or TGF- $\beta$ Ab's, but not by control Ab's $(P<0.05$, ANOVA).

In vivo transdifferentiation. STZ-induced diabetes in both rat strains was associated with reduced weight gain, and a marked increase in plasma glucose and $\mathrm{HbA1c}$ (Table 1). In control animals, $\alpha$-SMA staining

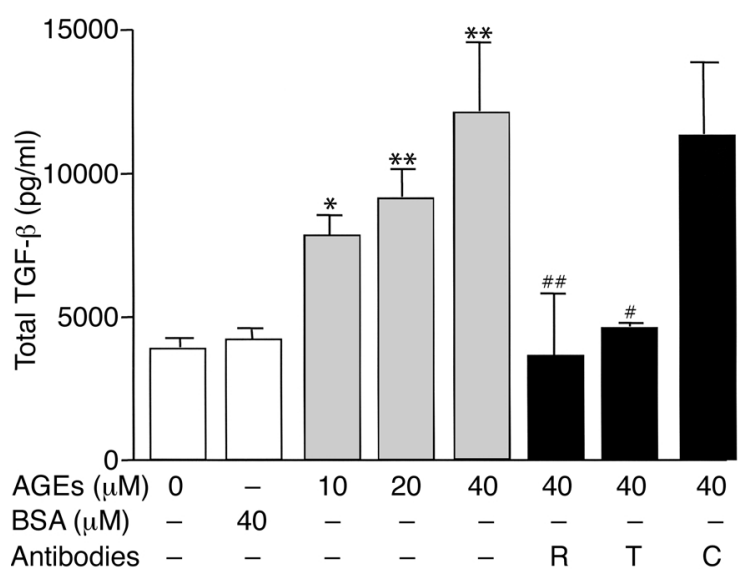

Figure 6

Effect of AGE-BSA exposure on total TGF- $\beta$ production. Total TGF- $\beta$ levels were measured by ELISA (mean \pm SEM). AGE-BSA, but not BSA, exposure caused a dose-dependent increase in TGF- $\beta$ protein levels at 3 days that was abrogated by the presence of either Ab's to RAGE (R) or TGF- $\beta(T)$, but not by control Ab's $(C) .{ }^{*} P<0.05,{ }^{*} P<0.01$ vs. AGEBSA $(0 \mu \mathrm{M})$; ${ }^{\#} P<0.05,{ }^{\# \#} P<0.01$ vs. AGE-BSA $(40 \mu \mathrm{M})$ by ANOVA. 

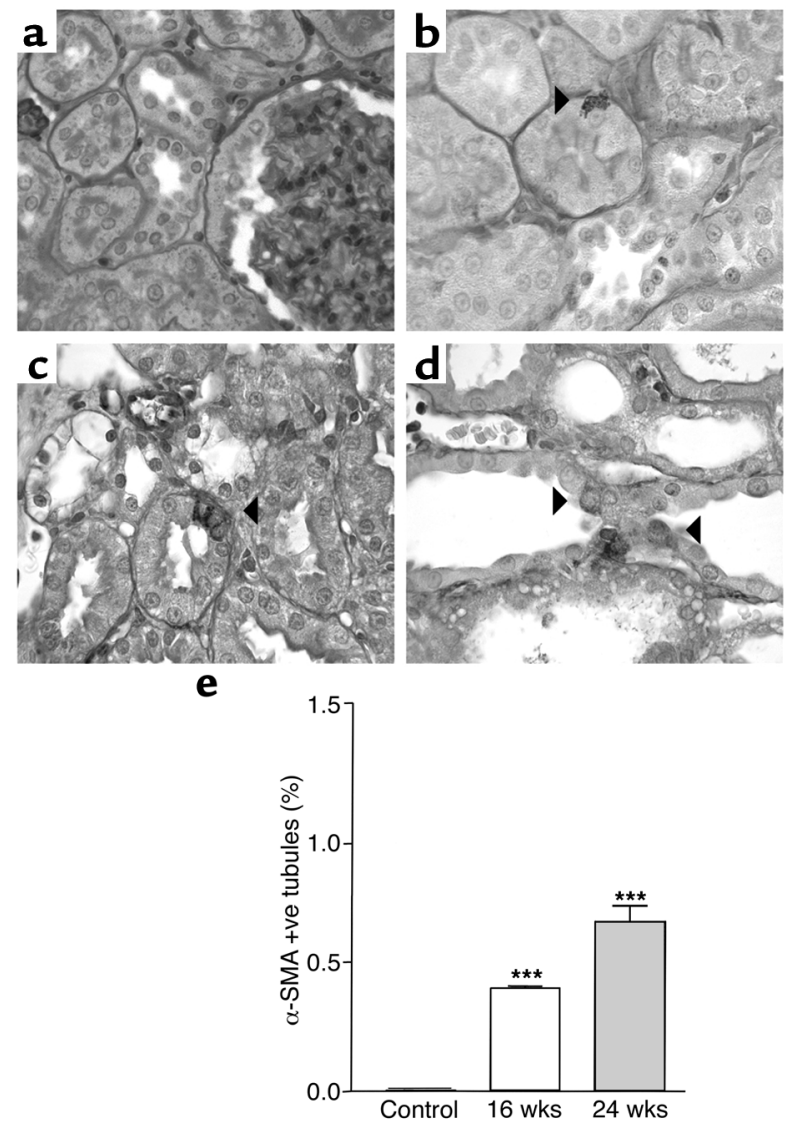

\section{Figure 7}

In vivo $\alpha$-SMA staining in the tubules of chronically diabetic rats. Kidney sections from WKY rats (control, 16- and 24-week diabetic) were stained for $\alpha$-SMA with a PAS counterstain. (a) In control animals $\alpha$-SMA staining was limited to vascular smooth muscle cells (arrow). Diabetes was associated with an increase in tubular $\alpha$-SMA expression at all time points: (b) 16 weeks and (c) 24 weeks of diabetes, $\alpha$-SMA +ve cell with a fibroblast phenotype within a disrupted proximal tubule (arrows). Original magnification, $\times 1,000$. Distal tubular staining was seen rarely (d) (arrows). (e) Proximal tubules were counted in control and diabetic WKY rat kidney sections (masked for identity, 20 high-power fields, $\times 400 ; n \geq 4$ per group). The number of tubules containing $\alpha$-SMA-positive cells is shown as a percentage of total tubule number (mean \pm SEM). ${ }^{* *} P<0.001$ compared with age-matched control using unpaired $t$ test.

was limited to vascular smooth muscle cells and an occasional interstitial cell (Figure 7a). The induction of diabetes caused a time-dependent increase in tubular $\alpha$-SMA staining. In the WKY rat strain, two time points were evaluated, with $\alpha$-SMA evident in 0.3 and $0.5 \%$ of tubules at 16 and 24 weeks respectively $(P<0.001$, Figure $7, b, c$, and e). After 32 weeks of diabetes, in the SD rat strain approximately $5 \%$ of tubules expressed $\alpha$-SMA (see Figure $9 \mathrm{e}$ and Figure $10, P<0.001, t$ test).

Proximal tubules were the major site of transdifferentiation in both rat strains, while unequivocal distal tubular staining occurred rarely (Figure $7 \mathrm{~d}$ ). Staining for $\alpha$-SMA in a STZ-treated rat that did not become diabetic was the same as control.
Evidence of increased proximal and distal tubule accumulation of AGEs was clearly seen in WKY rats (Figure 8). In addition, RAGE was detectable in both proximal and distal renal tubules (Figure 8, $\mathrm{c}$ and $\mathrm{d}$ ).

To further explore the importance of the AGE-RAGE pathway in in vivo transdifferentiation we studied a group of SD rats that received the specific AGE-crosslink breaking compound, ALT-711 (14). ALT 711 did not affect weight, fasting plasma glucose, or HbA1c, compared with the diabetic animals. In SD rats, there was increased accumulation of AGEs, which was ameliorated by the cross-link breaker ALT 711 (Figure 9).

As observed in WKY rats, $\alpha$-SMA staining was restricted to smooth muscle cells within blood vessels and occasional interstitial cells in nondiabetic rats. However, after 32 weeks of diabetes, in the SD rat strain approximately $5 \%$ of tubules expressed $\alpha$-SMA (Figure $9 \mathrm{e}$ and Figure 10; $P<0.001, t$ test). Diabetic animals that received ALT 711 had significant reductions in $\alpha$-SMA staining (Figure 9f and Figure 10). More significantly, the number of individual cells expressing $\alpha$-SMA within affected tubules was significantly reduced (67\% vs. $18 \%, P<0.01$; Figure 10b).

To further address the relationship of TGF- $\beta$ to transdifferentiation, TGF- $\beta$ immunostaining was evaluated and shown to be increased approximately threefold in the tubules of diabetic SD rats and reduced, though not normalized, by ALT-711 treatment (Figure 10c and Figure 11).

Human diabetic nephropathy. Evidence of tubular-epithelial myofibroblast transdifferentiation (TEMT) was also seen in a renal biopsy of a human type 1 diabetic subject with nephropathy (Figure 12a). Clear $\alpha$-SMA immunostaining of an epithelial cell within an intact tubule indicates an early stage in the transdifferentiation process in which there is expression of a mesenchymal marker before morphological change has taken place. In addition, AGE and RAGE were both clearly detectable, par-
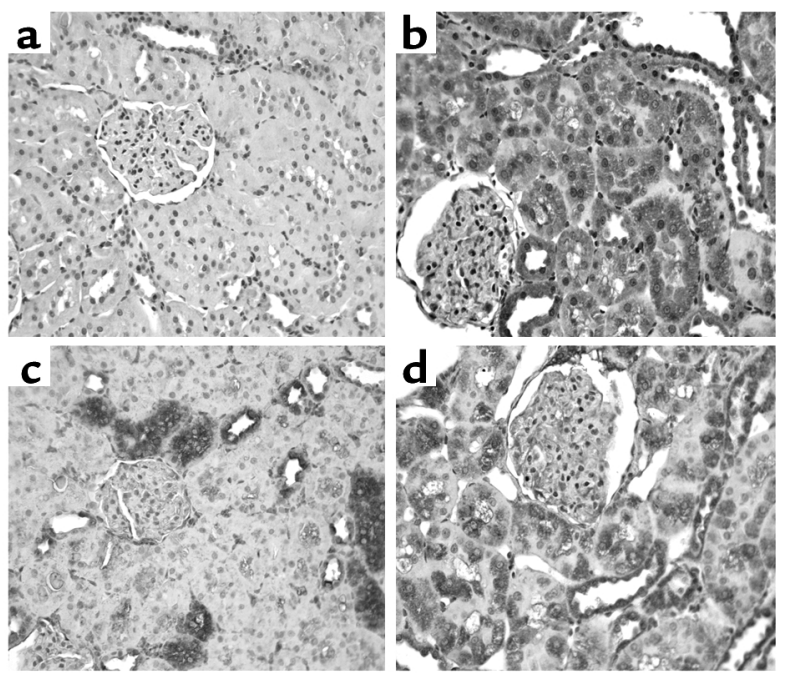

Figure 8

AGE and RAGE immunostaining in WKY rats. Kidney sections from 24-week WKY control and diabetic rats were stained for the presence of AGEs ( $\mathbf{a}$ and $\mathbf{b}$ ) and RAGE ( $\mathbf{c}$ and $\mathbf{d})$. 

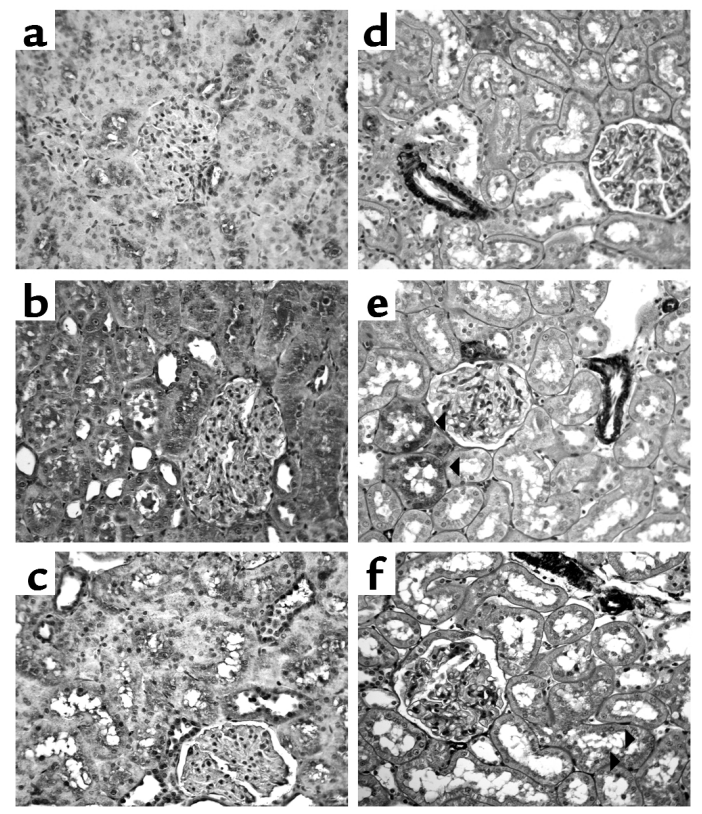

ticularly in tubules in a postmortem kidney sample from a diabetic patient with nephropathy and KimmelstielWilson lesions (Figure 12, b and c).

\section{Discussion}

Evidence has accumulated over the last decade implicating the formation of AGEs as a major factor in the pathogenesis of diabetic nephropathy $(2,3)$. The present study has identified a potential pathogenic pathway for the development of tubulointerstitial fibrosis in diabetic nephropathy.

It has been demonstrated that AGEs exert their effects in part through an interaction with specific cell surface-binding proteins. RAGE, a multiligand mem-

\section{Figure 9}

In vivo AGE and $\alpha$-SMA staining in the tubules of chronically diabetic rats. Kidney sections from SD rats, control, 32-week diabetic, and 32-week diabetic that received the AGE-cross-link breaker, ALT $711(n=5$ each group), were stained for AGE and separately for $\alpha$-SMA. Representative pictures of AGE staining in (a) control, (b) diabetic, and (c) diabetic animals that received ALT 711. (d and e) $\alpha$-SMA staining. In control animals $\alpha$-SMA staining was limited to vascular smooth muscle cells $(\mathbf{d})$. Diabetes was associated with an increase in tubular $\alpha$-SMA staining (e) (arrowheads) that was ameliorated in diabetic animals receiving ALT 711 (f). $P<0.05$, magnification for all $\times 400$.

ber of the immunoglobulin superfamily is the best characterized of the AGE receptors (37). Purified RAGE migrates as a single band on SDS-PAGE, but has been shown to appear as a doublet due to posttranslational modification of the molecule (29). The lower-molecular-weight binding site detected with ligand blotting was initially considered possibly to represent the presence of lysozyme in our membrane preparation, because lysozyme has been shown previously to bind AGEs (36). Immunoblotting failed to confirm this, and the identity of the band remains unclear and may represent a RAGE breakdown product. However, the relative importance of the binding sites seen in this study, and specifically the relevance of the AGE-RAGE interaction, was further confirmed by the ability of a wellcharacterized neutralizing $\mathrm{Ab}$ to RAGE to prevent AGE-mediated transdifferentiation.

Recently, mesangial cells and smooth muscle cells have both been shown to produce TGF- $\beta$ when exposed to AGEs $(8,38)$. Although RAGE has been independently detected at both sites $(29,39)$, the receptor was not explicitly identified in the aforementioned studies. The present study clearly identified TGF- $\beta$ generation in response to an interaction between AGEs and RAGE.

\section{Figure 10}

Quantitation of in vivo $\alpha$-SMA and TGF- $\beta$ staining. Kidney sections from SD rats, control, 32-week diabetic, and 32-week diabetic + ALT 711 ( $n=5$ each) were examined. (a) The number of $\alpha$-SMA +ve tubules counted in 20 or more high-power fields $(\times 200$; $\geq 600$ tubules) is expressed as a percentage of total tubule number. ${ }^{* *} P<0.001 \mathrm{com}$ pared with control, ${ }^{\#} P<0.05$ compared with diabetic, using unpaired $t$ test. (b) In addition, the number of individual tubular cells that stained for $\alpha$-SMA in affected tubules were counted and are expressed as a percentage of total tubular cell number, $\#$ \# $P<0.01$ compared with diabetic. (c) TGF- $\beta$ immunostaining. Diabetes was associated with a significant increase in TGF- $\beta$ immunostaining that was ameliorated, but not normalized by ALT 711 treatment. The tubular TGF- $\beta$ staining was quantitated by a computer-based imaging system. Results are expressed as a proportion of total area; $n=5$ animals per group.

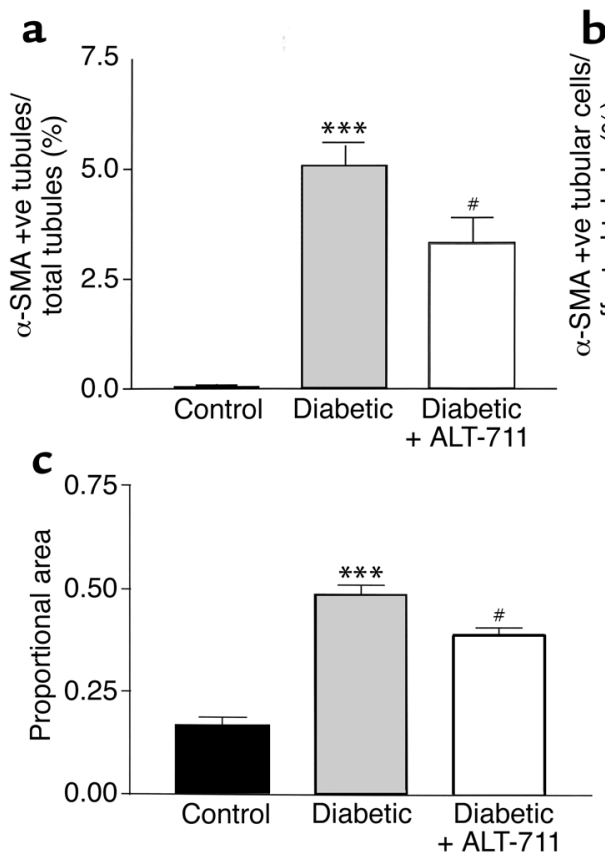




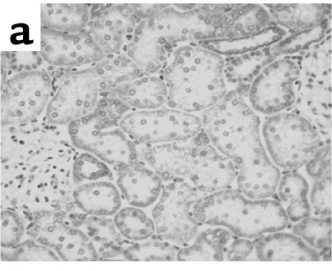

Control

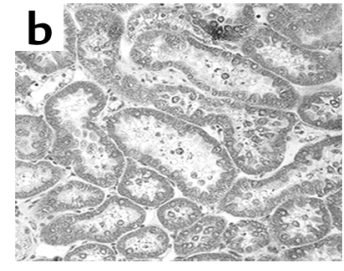

Diabetic

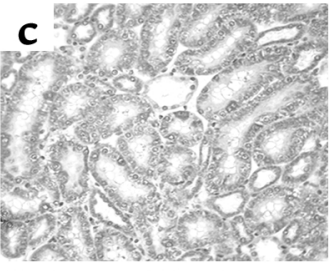

Diabetic + ALT-711

Figure 11

TGF- $\beta$ immunostaining in the SD rats. Diabetes was associated with a marked increase in TGF- $\beta$ immunostaining (b) when compared with controls (a). This increase was ameliorated by treatment with ALT 711 (c). Representative pictures are shown at magnification $\times 400$.

AGE-RAGE-mediated transdifferentiation appeared to be dependent upon the production of TGF- $\beta$. This cytokine is considered to be highly important in the phenomenon of myofibroblast transdifferentiation and has been shown to cause the acquisition of myofibroblast characteristics in fibroblasts (40). Similar changes in cell morphology and antigen expression have been observed in studies of TGF- $\beta(10-50 \mathrm{ng} / \mathrm{ml})$ administration to the NRK 52E cell line (20). These phenotypic alterations were associated with ultrastructural changes, the appearance of stress fibers, and a new front-to-back polarity, typical of the development of a myofibroblast phenotype. Furthermore, all these changes could be prevented by the inhibition of TGF- $\beta$ with a neutralizing $A b$.

AGE-RAGE interaction has also been demonstrated to induce the production of a number of other cytokines such as IL-1 and PDGF $(8,9)$. This study cannot exclude a role for these other cytokines in mediating the observed transdifferentiation; indeed, IL-1 has been reported to induce transdifferentiation in this cell line (41). This action of IL- 1 is probably mediated via the induction of TGF- $\beta$ (42).

To further explore the relevance of these findings to the in vivo context, the effects of CML-BSA, one of a number of AGE modifications known to occur in vivo were evaluated. This AGE has been demonstrated to bind to RAGE, activating intracellular transcription factors (22). In our system, the culture of cells with CMLBSA was associated with an increase in $\alpha$-SMA expression in a dose- and modification-dependent manner, although with less effect than exogenous AGEs on phenotypic changes of these cells. AGEs in vitro and in vivo constitute a heterogeneous group of protein modifications and the present study suggests that the changes seen with exogenous AGE administration cannot be fully explained by CML. However, the degree of transdifferentiation that occurs in vivo would be consistent with the effects of endogenous AGEs such as CML. Indeed the major epitope recognized by the $\mathrm{Ab}$ used in the present study to detect increased AGEs in diabetic tubules is CML-bound to proteins (12).

The proximal tubules in diabetes are potentially exposed to high levels of AGE-peptides due to active proximal tubular reabsorption and catabolism (43). Indeed binding of AGEs to the proximal tubules appears to increase in diabetes (44), and increased glomerular and tubular AGE staining was seen in this study, confirming previous observations using both immunohistochemical and radioimmunoassay techniques (34). AGEs were shown to induce in vitro epithelial-mesenchymal transdifferentiation in a time- and dose-dependent manner, and proximal tubular transdifferentiation was seen to increase with duration of diabetes in these rat models.

To further explore the role of this pathway in vivo, a group of SD rats were studied that had received the cross-link breaker, ALT 711. This class of agents has been shown to cleave preformed AGEs (11) and in the diabetic milieu to reduce AGE accumulation (12). More recently, ALT 711 has been shown to improve vascular compliance in diabetic rats (14). In the present study, ALT 711 was associated with reduced renal

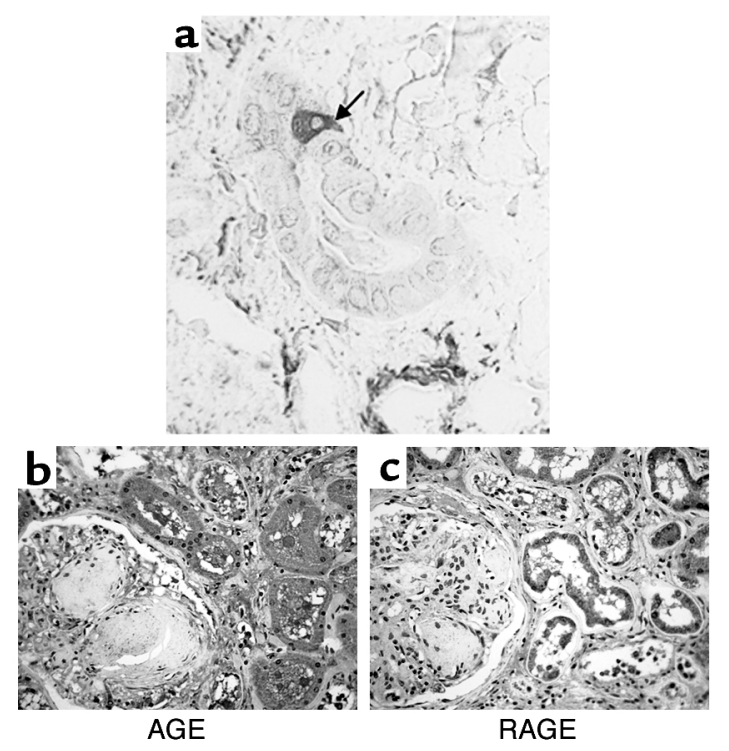

Figure 12

Evidence of transdifferentiation in a case of human diabetic nephropathy. A patient with type 1 diabetes of 15 years' duration was diagnosed with nodular diabetic glomerulosclerosis and moderate interstitial fibrosis and tubular atrophy upon biopsy. (a) Clear cytoplasmic immunostaining for $\alpha$-SMA is apparent in a single epithelial cell (arrow) within an intact tubule. (b and $\mathbf{c}$ ) AGE and RAGE immunostaining. A postmortem kidney section from a patient with diabetic nephropathy and Kimmelstiel-Wilson nodules was stained for AGE (b) and RAGE (c). Original magnification for all $\times 400$. 
AGE accumulation. The reduction in AGE staining was associated with both reduced TGF- $\beta$ immunostaining and less transdifferentiation, as evidenced by decreased number of $\alpha$-SMA +ve tubular cells. This is consistent with the hypothesis that AGEs in vivo are associated with epithelial to myofibroblast transformation. It should be noted that while $\alpha$-SMA and TGF- $\beta$ immunostaining were both reduced by ALT 711 treatment, neither were completely normalized, suggesting that other mechanisms may be involved. The likelihood that these effects are mediated via reduction of AGEs, rather than effects on hyperglycemia per se, are supported by a lack of effect of this agent on plasma glucose or the Amadori product HbA1c.

RAGE distribution in tubules has been demonstrated by a number of groups. Brett, et al., detected RAGE in the proximal but not the distal convoluted tubule (29), whereas our group and others had previously localized immunostainable RAGE predominantly, but not exclusively, to the distal tubules $(28,45)$. In the present study, diabetes was associated with an accumulation of RAGE in both proximal and distal tubules in both the rat model and in human postmortem specimens using an anti-human RAGE Ab. The specificity of this well-characterized $\mathrm{Ab}$ has been confirmed by antigen preincubation with recombinant forms of human RAGE having been shown previously to negate $\mathrm{Ab}$ recognition of $\operatorname{RAGE}(29,45,46)$. However, the status of RAGE in proximal tubules remains controversial, because a recent study failed to find evidence of RAGE gene expression by RT-PCR in purified proximal tubules obtained from diabetic subjects (47). This discrepancy between gene and protein expression requires further study and may relate to differences in sensitivity and specificity for the various techniques used.

TGF- $\beta$ expression is increased in the diabetic kidney and is increasingly recognized as playing a central role in the development of diabetic nephropathy and tubulointerstitial fibrosis (48). All three isoforms of TGF- $\beta$ have been reported to be upregulated in the tubulointerstitium in diabetes (49), and studies of the TGF- $\beta$-inducible gene $\beta i g-H 3$ have demonstrated that a major site for increased TGF- $\beta$ activity in diabetes is in tubules (50). A further study using a novel inhibitor of AGE formation, OPB 9195, has also shown a reduction in the diabetes-associated increase in TGF- $\beta$ in parallel with reduced AGE accumulation (51). Considering the pivotal role that TGF- $\beta$ plays in the phenomenon of epithelial-mesenchymal transdifferentiation (20), colocalization of AGEs, RAGE, and TGF- $\beta$ in tubules in association with transdifferentitaion suggests a similar phenomenon may occur in vivo.

In a previous study, $\alpha$-SMA staining was detected in the proximal tubular cells of diabetic animals (52), although this was not quantitated. In the same study another mesenchymal marker, vimentin, was noted to be present in at least $2 \%$ of proximal tubular cells at approximately 16 weeks. In another in vivo model of renal disease, the remnant model was associated with up to $5 \%$ of cortical tubules expressing $\alpha$-SMA (53). In the present study, after 32 weeks of experimental diabetes, a similar degree of transdifferentiation was observed.

In the human, a renal biopsy stained for evidence of tubular transdifferentiation convincingly identified the phenomenon in a diabetic patient. A more rigorous evaluation of transdifferentiation in diabetic patients with varying degrees of diabetic nephropathy and, in particular, differences in the presence and degree of tubulointerstitial fibrosis is now warranted. Since diabetic renal disease is a process that occurs slowly over many decades in only a minority of diabetic patients, it is likely that a very detailed evaluation of this phenomenon in human biopsies will be required to determine the relevance of TEMT in this condition. This issue is of major clinical relevance with diabetic nephropathy now the major cause of end-stage renal failure in the Western world, and the pathogenesis of tubulointerstitial fibrosis and its relationship to glucose-dependent events not fully defined.

This study has provided evidence that AGEs mediate tubular to myofibroblast transdifferentiation through RAGE in vitro and that this effect is dependent upon the prosclerotic cytokine TGF- $\beta$. Furthermore, this phenomenon was observed in the tubules of chronically diabetic rats, was detected in a human diabetic nephropathy specimen, and was attenuated by an inhibitor of AGE accumulation. This study provides evidence that an AGE-dependent pathway may play a role in the development of tubulointerstitial fibrosis in the diabetic kidney.

\section{Acknowledgments}

This work is supported by a Centre grant from the Juvenile Diabetes Research Foundation International.

1. Brownlee, M., Vlassara, H., and Cerami, A. 1984. Nonenzymatic glycosylation and the pathogenesis of diabetic complications. Ann. Intern. Med. 101:527-537.

2. Vlassara, H., et al. 1994. Advanced glycation end products induce glomerular sclerosis and albuminuria in normal rats. Proc. Natl. Acad. Sci. USA. 91:11704-11708.

3. Soulis-Liparota, T., Cooper, M., Papazoglou, D., Clarke, B., and Jerums, G. 1991. Retardation by aminoguanidine of development of albuminuria, mesangial expansion, and tissue fluorescence in streptozocininduced diabetic rat. Diabetes. 40:1328-1334.

4. Neeper, M., et al. 1992. Cloning and expression of a cell surface receptor for advanced glycosylation end products of proteins. J. Biol. Chem. 267:14998-15004.

5. Vlassara, H., et al. 1995. Identification of galectin-3 as a high-affinity binding protein for advanced glycation end products (AGE): a new member of the AGE-receptor complex. Mol. Med. 1:634-646.

6. el Khoury, J., et al. 1994. Macrophages adhere to glucose-modified basement membrane collagen IV via their scavenger receptors. J. Biol. Chem. 269:10197-10200.

7. Yang, Z., et al. 1991. Two novel rat liver membrane proteins that bind advanced glycosylation endproducts: relationship to macrophage receptor for glucose-modified proteins. J. Exp. Med. 174:515-524.

8. Throckmorton, D.C., Brogden, A.P., Min, B., Rasmussen, H., Kashgarian, M. 1995. PDGF and TGF-beta mediate collagen production by mesangial cells exposed to advanced glycosylation end products. Kidney Int. 48:111-117.

9. Vlassara, H., Brownlee, M., Manogue, K.R., Dinarello, C.A., and Pasagian, A. 1988. Cachectin/TNF and IL-1 induced by glucose-modified proteins: role in normal tissue remodeling. Science. 240:1546-1548.

10. Yan, S.D., et al. 1994. Enhanced cellular oxidant stress by the interaction of advanced glycation end products with their receptors/binding proteins. J. Biol. Chem. 269:9889-9897. 
11. Vasan, S., et al. 1996. An agent cleaving glucose-derived protein crosslinks in vitro and in vivo. Nature. 382:275-278.

12. Cooper, M.E., et al. 2000. The cross-link breaker, N-phenacylthiazolium bromide prevents vascular advanced glycation end-product accumulation. Diabetologia. 43:660-664.

13. Asif, M., et al. 2000. An advanced glycation endproduct cross-link breaker can reverse age-related increases in myocardial stiffness. Proc. Natl. Acad. Sci. USA. 97:2809-2813.

14. Wolffenbuttel, B.H., et al. 1998. Breakers of advanced glycation end products restore large artery properties in experimental diabetes. Proc. Natl. Acad. Sci. USA. 95:4630-4634.

15. Ziyadeh, F.N., and Goldfarb, S. 1991. The renal tubulointerstitium in diabetes mellitus. Kidney Int. 39:464-475.

16. Taft, J.L., Nolan, C.J., Yeung, S.P., Hewitson, T.D., and Martin, F.I. 1994 Clinical and histological correlations of decline in renal function in diabetic patients with proteinuria. Diabetes. 43:1046-1051.

17. Hogemann, B., Gillessen, A., Bocker, W., Rauterberg, J., and Domschke, W. 1993. Myofibroblast-like cells produce mRNA for type I and III procollagens in chronic active hepatitis. Scand. J. Gastroenterol. 28:591-594.

18. Pedagogos, E., Hewitson, T., Fraser, I., Nicholls, K., and Becker, G. 1997. Myofibroblasts and arteriolar sclerosis in human diabetic nephropathy. Am. J. Kidney Dis. 29:912-918.

19. Strutz, F., and Muller, G.A. 2000. Transdifferentiation comes of age. Nephrol. Dial. Transplant. 15:1729-1731.

20. Fan, J.M., et al. 1999. Transforming growth factor-beta regulates tubular epithelial-myofibroblast transdifferentiation in vitro. Kidney Int. 56:1455-1467

21. Vlassara., H., Brownlee, M., and Cerami, A. 1985. High-affinity-receptormediated uptake and degradation of glucose-modified proteins: a potential mechanism for the removal of senescent macromolecules. Proc. Natl. Acad. Sci. USA. 82:5588-5592.

22. Kislinger, T., et al. 1999. N(epsilon)-(carboxymethyl)lysine adducts of proteins are ligands for receptor for advanced glycation end products that activate cell signaling pathways and modulate gene expression. $J$. Biol. Chem. 274:31740-31749.

23. Cayot, P., and Tainturier, G. 1997. The quantification of protein amino groups by the trinitrobenzenesulfonic acid method: a reexamination. Anal. Biochem. 249:184-200

24. Greenwood, P.C., Hunter, W.M., and Glover, J.S. 1963. The preparation of 131I-labelled human growth hormone of high specific radioactivity. Biochem. J. 89:114-123.

25. Skolnik, E.Y., et al. 1991. Human and rat mesangial cell receptors for glucose-modified proteins: potential role in kidney tissue remodelling and diabetic nephropathy. J. Exp. Med. 174:931-939.

26. Bradford, M. 1976. A rapid and sensitive method for quantification of microgram quantities of protein utilising the principle of protein dye binding. Ann. Biochem. 72:248-254.

27. Munson, P.J. 1983. LIGAND: a computerized analysis of ligand binding data. Methods Enzymol. 92:543-576.

28. Soulis, T., et al. 1997. Advanced glycation end products and their receptors co-localise in rat organs susceptible to diabetic microvascular injury. Diabetologia. 40:619-628.

29. Brett, J., et al. 1993. Survey of the distribution of a newly characterized receptor for advanced glycation end products in tissues. Am. J. Pathol. 143:1699-1712.

30. Goumenos, D.S., Brown, C.B., Shortland, J., and el Nahas, A.M. 1994 Myofibroblasts, predictors of progression of mesangial IgA nephropathy? Nephrol. Dial Transplant. 9:1418-1425.

31. Alpers, C.E., Hudkins, K.L., Floege, J., and Johnson, R.J. 1994. Human renal cortical interstitial cells with some features of smooth muscle cells participate in tubulointerstitial and crescentic glomerular injury. J. Am. Soc. Nephrol. 5:201-209.

32. Bacallao, R., Kiai, K., and Jesaitis, L. 1995. Guiding principles of speci- men preservation for confocal fluorescence microscopy. In Handbook of biological confocal microscopy. J.P. Pawley, editor. Plenum Press. New York, New York, USA. 311-323.

33. Cooper, M.E., et al. 1988. Effects of genetic hypertension on diabetic nephropathy in the rat - functional and structural characteristics. J. Hypertens. 6:1009-1016.

34. Soulis, T., Cooper, M.E., Vranes, D., Bucala, R., and Jerums, G. 1996. Effects of aminoguanidine in preventing experimental diabetic nephropathy are related to the duration of treatment. Kidney Int. 50:627-634.

35. Forbes, J.M., et al. 2001. Renoprotective effects of a novel inhibitor of advanced glycation. Diabetologia. 44:108-114.

36. Li, Y.M., Tan, A.X., and Vlassara, H. 1995. Antibacterial activity of lysozyme and lactoferrin is inhibited by binding of advanced glycationmodified proteins to a conserved motif. Nat. Med. 1:1057-1061.

37. Schmidt, A.M., et al. 1992. Isolation and characterization of two binding proteins for advanced glycosylation end products from bovine lung which are present on the endothelial cell surface. J. Biol. Chem. 267:14987-14997.

38. Higashi, T., et al. 1997. The receptor for advanced glycation end products mediates the chemotaxis of rabbit smooth muscle cells. Diabetes. 46:463-472.

39. Ritthaler, U., et al. 1995. Expression of receptors for advanced glycation end products in peripheral occlusive vascular disease. Am. J. Pathol. 146:688-694.

40. Desmouliere, A., Geinoz, A., Gabbiani, F., and Gabbiani, G. 1993. Transforming growth factor-beta 1 induces alpha-smooth muscle actin expression in granulation tissue myofibroblasts and in quiescent and growing cultured fibroblasts. J. Cell Biol. 122:103-111.

41. Fan, J.M., et al. 2001. Interleukin-1 induces tubular epithelial-myofibroblast transdifferentiation through a transforming growth factorbeta1-dependent mechanism in vitro. Am. J. Kidney Dis. 37:820-831.

42. Phillips, A.O., Topley, N., Steadman, R., Morrisey, K., and Williams, J.D. 1996. Induction of TGF-beta 1 synthesis in D-glucose primed human proximal tubular cells by IL-1 beta and TNF alpha. Kidney Int. 50:1546-1554.

43. Gugliucci, A., and Bendayan, M. 1996. Renal fate of circulating advanced glycated end products (AGE): evidence for reabsorption and catabolism of AGE-peptides by renal proximal tubular cells. Diabetologia. 39:149-160.

44. Youssef, S., et al. 1999. Effect of diabetes and aminoguanidine therapy on renal advanced glycation end-product binding. Kidney Int. 55:907-916.

45. Abel, M., et al. 1995. Expression of receptors for advanced glycosylated end-products in renal disease. Nephrol. Dial Transplant. 10:1662-1667.

46. Schmidt, A.M., et al. 1994. The endothelial cell binding site for advanced glycation end products consists of a complex: an integral membrane protein and a lactoferrin-like polypeptide. J. Biol. Chem. 269:9882-9888.

47. Tanji, N., et al. 2000. Expression of advanced glycation end products and their cellular receptor RAGE in diabetic nephropathy and nondiabetic renal disease. J. Am. Soc. Nephrol. 11:1656-1666.

48. Reeves, W.B., and Andreoli, T.E. 2000. Transforming growth factor beta contributes to progressive diabetic nephropathy. Proc. Natl. Acad. Sci. USA. 97:7667-7669.

49. Yamamoto, T., et al. 1996. Expression of transforming growth factorbeta isoforms in human glomerular diseases. Kidney Int. 49:461-469.

50. Gilbert, R.E., et al. 1998. Renal expression of transforming growth factor-beta inducible gene-h3 (beta ig-h3) in normal and diabetic rats. Kidney Int. 54:1052-1062.

51. Tsuchida, K., et al. 1999. Suppression of transforming growth factor beta and vascular endothelial growth factor in diabetic nephropathy in rats by a novel advanced glycation end product inhibitor, OPB-9195. Diabetologia. 42:579-588.

52. Sanai, T., et al. 2000. Expression of cytoskeletal proteins during the course of experimental diabetic nephropathy. Diabetologia. 43:91-100.

53. Ng, Y.Y., et al. 1998. Tubular epithelial-myofibroblast transdifferentiation in progressive tubulointerstitial fibrosis in $5 / 6$ nephrectomized rats. Kidney Int. 54:864-876. 